\title{
Platinum-group and other traffic-related heavy metal contamination in road sediment, Guangzhou, China
}

\author{
Lifeng Zhong • Jie Li • Wen Yan • Xianglin Tu • \\ Weixia Huang $\cdot$ Xiaohua Zhang
}

Received: 11 October 2011 / Accepted: 9 April 2012 / Published online: 26 April 2012

(C) The Author(s) 2012. This article is published with open access at Springerlink.com

\begin{abstract}
Purpose Human exposure to particulate matter emitted from on-road motor vehicles includes complex mixtures of heavy metals from tyres, brakes, part wear, and resuspended road sediment. The purpose of this study was to determine the concentrations of 14 platinum-group and other trafficrelated heavy metals in road sediment within the metropolitan area of Guangzhou, China, with a view to identifying their sources and assessing the extent of anthropogenic influence on heavy metal contamination of road sediment. Materials and methods Thirty-five samples of road sediment were collected. The concentrations of $\mathrm{Cr}, \mathrm{Mn}, \mathrm{Ni}$, $\mathrm{Cu}, \mathrm{Zn}, \mathrm{La}, \mathrm{Ce}, \mathrm{Mo}, \mathrm{Cd}, \mathrm{Pb}, \mathrm{Ba}$, and $\mathrm{Rh}$ were measured by inductively coupled plasma-mass spectrometry. Pt and $\mathrm{Pd}$ were analyzed by isotopic dilution-inductively coupled plasma-mass spectrometry. Multivariate statistical analysis and enrichment factor methods were employed to identify the sources of these heavy metals and to assess anthropogenic influences on their occurrence.

Results and discussion The mean concentrations of $\mathrm{Pt}, \mathrm{Pd}$, $\mathrm{Rh}, \mathrm{Cr}, \mathrm{Mn}, \mathrm{Ni}, \mathrm{Cu}, \mathrm{Zn}, \mathrm{La}, \mathrm{Ce}, \mathrm{Mo}, \mathrm{Cd}, \mathrm{Pb}$, and $\mathrm{Ba}$ in the
\end{abstract}

Responsible editor: Ian Droppo

Electronic supplementary material The online version of this article (doi:10.1007/s11368-012-0527-8) contains supplementary material, which is available to authorized users.

L. Zhong $\cdot$ W. Yan $(\bowtie) \cdot$ W. Huang $\cdot$ X. Zhang

CAS Key Laboratory of Marginal Sea Geology, South China Sea

Institute of Oceanology, Chinese Academy of Sciences,

Guangzhou 510301, People's Republic of China

e-mail:wyan@scsio.ac.cn

J. Li $\cdot$ X. Tu

Guangzhou Institute of Geochemistry,

Chinese Academy of Sciences,

Guangzhou 510640, People's Republic of China road sediment samples were $68.24,93.15,23.85,147.5$, 712.3, 47.24, 177.5, 1254, 47.50, 96.62, 4.91, 3.00, 198.1, and $641.3 \mathrm{ng} \mathrm{g}^{-1}$, respectively. Very weak to significant linear positive correlations were found among the various heavy metals. The elemental composition of road sediment was dominated by five principal components. Three clusters were identified through cluster analysis, and enrichment factors were calculated relative to soils in China. The sources and degree of contamination of the heavy metals are discussed based on the results.

Conclusions The mean concentrations of heavy metals are higher than background values, especially for $\mathrm{Pt}, \mathrm{Pd}, \mathrm{Rh}$, $\mathrm{Cd}$, and Zn. Four main sources are identified: (1) Pt, Pd, and $\mathrm{Rh}$ were derived from traffic sources; (2) $\mathrm{La}, \mathrm{Ce}, \mathrm{Mn}$, and Ba were derived mainly from natural sources; (3) $\mathrm{Cr}, \mathrm{Ni}, \mathrm{Cu}$, $\mathrm{Mo}, \mathrm{Cd}$, and $\mathrm{Pb}$ showed mixed traffic-industry sources; and (4) $\mathrm{Zn}$ originated mainly from industrial sources. Enrichment factor analysis supported this source identification and further indicated that contamination of road sediment in Guangzhou is extremely high for Pt, Pd, and $\mathrm{Rh}$; moderate to very high for $\mathrm{Cd}, \mathrm{Zn}, \mathrm{Pb}, \mathrm{Cu}$, and $\mathrm{Mo}$; and minimal for $\mathrm{Cr}, \mathrm{Ni}, \mathrm{La}, \mathrm{Ce}$, and $\mathrm{Ba}$.

Keywords Enrichment factor · Guangzhou - Heavy metals · Multivariate statistical analysis · Platinum-group elements . Road sediment

\section{Introduction}

The worldwide production of platinum-group elements (PGEs) has risen steadily over the past three decades to meet demand from the automotive, chemical, dental, electronic, glass, pharmaceutical, and petroleum industries (Jollie 2010). In particular, the metals platinum (Pt), 
palladium $(\mathrm{Pd})$, and rhodium $(\mathrm{Rh})$ are widely used in vehicle exhaust catalysts (VECs) to convert noxious gases into more environmentally friendly forms. While VECs help improve air quality in general, they have become a primary source of $\mathrm{Pt}, \mathrm{Pd}$, and $\mathrm{Rh}$ in the environment. This has led to increased concentrations of these metals in a variety of environmental media. For example, concentrations as high as $2,522 \mathrm{ng} \mathrm{g}^{-1}$ of Pt and $516 \mathrm{ng} \mathrm{g}^{-1}$ of Pd have been recorded in road sediment (Gómez et al. 2001; Leopold et al. 2008).

In addition to PGEs, other elements such as $\mathrm{Ce}, \mathrm{La}$, $\mathrm{Mo}$, and $\mathrm{Ni}$ are used in vehicle exhaust converters (Baldanza et al. 2000; Gandhi et al. 2003; Morcelli et al. 2005; Zotin et al. 2005). These metals can be emitted to the atmosphere (in small quantities) together with particles from the washcoat component of catalytic converters as a result of chemical and physical stresses such as sintering and thermal shock (Artelt et al. 1999; Palacios et al. 2000). Other traffic-related elements (TRE) found in city environments include $\mathrm{Ba}$, $\mathrm{Cd}, \mathrm{Cr}, \mathrm{Cu}, \mathrm{Mn}, \mathrm{Zn}$, and $\mathrm{Pb}$. The sources of these heavy metals include exhaust emissions, lubrication losses, and the degradation of vehicle tyres, brake linings, and motorway surfaces (Hares and Ward 1999). For example, $\mathrm{Cu}$, which is used as a component in brakepad materials, is a public health concern because the dust produced from brake wear (particle size of 1$10 \mu \mathrm{m}$ ) is partially inhalable (Birmili et al. 2006). Ni is associated with vehicular emissions, since it is used as a fuel additive (Park and Kim 2005) and is used in automotive catalytic converters to minimize $\mathrm{H}_{2} \mathrm{~S}$ emissions (Zotin et al. 2005). Pb can also be emitted from the combustion of leaded gasoline (Zheng et al. 2004), mechanical attrition (Salma and Maenhaut 2006), and the incineration of vehicle tires (Gieré et al. 2006). In 1997, metropolitan cities including Beijing, Shanghai, and Guangzhou began to use unleaded gasoline, and in 2000, China prohibited the sale and use of leaded gasoline.

Most of the traffic-related heavy metals are non-essential nutrients for humans and animals. Exposure to these metals has been associated with adverse health effects. Indications of the acute toxicity of several PGE-chlorinated salts and evidence of DNA damage due to PGE exposure have been observed both in vitro and in vivo (Gagnon et al. 2006). Although some traffic-related heavy metals, such as $\mathrm{Cu}, \mathrm{Zn}$, and $\mathrm{Mn}$, are essentially trace nutrients in humans and animals, excessive exposure has long been known to elicit toxicity in humans of all ages. For example, Mn presents a conundrum for risk assessment because it is both an essential trace element and a potent neurotoxicant (Weiss 2006). Its neurotoxic properties emerge almost exclusively from inhalation exposure, although it has been suggested that children are at risk of Mn-induced neurotoxicity via drinking water (Wasserman et al. 2006), and infant mortality may be related to Mn exposure (Hafeman et al. 2007).

Guangzhou, which is the capital of Guangdong Province in China and is part of the Pearl River Delta (PRD) region, is the largest industrial center in China and one of the fastest growing cities. The city has experienced a tremendous increase in motorized traffic volume since 2000 , with above 1.5 million vehicles on the road. Rapid economic development over the past three decades has brought great prosperity to the region, but has also led to environmental problems. The decline in regional environmental quality since the late 1980s has spurred extensive research in the area, including that of the concentration, distribution, partitioning, sources, and enrichment of heavy metal contaminants (e.g., Wong et al. 2003; Duzgoren-Aydin et al. 2006a,b; Duzgoren-Aydin 2007; Lee et al. 2007; Li et al. 2009). In particular, recent studies of road sediment in Guangzhou have reported that the level and extent of $\mathrm{Zn}$ contamination is more severe and widespread than that for other trace metals such as $\mathrm{Cd}, \mathrm{Cu}$, and $\mathrm{Pb}$ (Duzgoren-Aydin et al. 2006b).

Road sediment (also called "street dust" or "road dust") is a complex mixture of particles from a number of natural and anthropogenic sources, including tyre and brake wear; exhaust fumes; road surface abrasion; corrosion particles from vehicles; and particles from various diffuse sources, such as waste incineration, fossil-fuel power plants, and building materials. Heavy metals can accumulate in road sediment through atmospheric deposition. As a sink or source, road sediment is therefore a good indicator of the level and extent of heavy metal accumulation in the surface environment (Duzgoren-Aydin et al. 2006a; Taylor and Owens 2009). The advantages of using road sediment as a source of environmental information include its ubiquitous nature, ease of sampling, strong association with automobile emissions, and its relationship with nonpoint-source pollution (Sutherland 2003). Many studies of PGEs or heavy metal concentrations have been carried out using road sediment (e.g., Zereini et al. 2001; Leopold et al. 2008; Joshi et al. 2009; Prichard et al. 2009; Qiu et al. 2009; Lu et al. 2010; Apeagyei et al. 2011), but few have examined platinum-group and other traffic-related heavy metals (e.g., Pratt and Lottermoser 2007; da Silva et al. 2008).

The primary objectives of this preliminary study were to (1) determine the concentrations of 14 platinum-group and other traffic-related heavy metals in road sediment collected from different urban settings within the metropolitan area of Guangzhou, China; (2) identify the natural or anthropogenic sources of these heavy metals using multivariate statistical analysis; and (3) assess the extent of anthropogenic influence on heavy metal contamination of road sediment using enrichment factors (EFs). 


\section{Materials and methods}

\subsection{Reference materials and equipment}

Three reference materials with different lithological characteristics were analyzed to assess the accuracy of the analytical method used to detect PGEs, as described in Section 2.3: (1) stream sediment from the National Research Center for Geoanalysis, China (GPt-2); (2) basalt from the US Geological Survey (BHVO-2); and (3) altered peridotite from the Canadian Certified Reference Materials Project (WPR-1). Two isotopic spikes (Pd and Pt metal power enriched with ${ }^{105} \mathrm{Pd}$ and ${ }^{194} \mathrm{Pt}$, respectively) were obtained from Oak Ridge National Laboratory, USA. Cation resin AG50W-X8 (200-400 mesh) was obtained from Bio-Rad Laboratories Inc., USA, and $N$-benzoyl- $N$-phenylhydroxylamine (BPHA) was obtained from Aladdin Reagent Inc., China. Pure water from a Milli-Q system (Millipore Corp., Millford, USA) and acids ( $\mathrm{HCl}, \mathrm{HNO}_{3}$, and $\mathrm{HF}$ ) from a subboiling distillation system were also used. A quadrupole inductively coupled plasma-mass spectrometer (ICP-MS; Elan 6000 , PE Inc.) was used for the analysis of PGEs and other heavy metal elements.

\subsection{Sample collection and pretreatment}

Guangzhou has a mild subtropical climate with hot and humid summers (April-September) and relatively cool and dry winters (October-March). Mean temperatures in July and January are 28.5 and $13.3{ }^{\circ} \mathrm{C}$, respectively. Annual total rainfall is approximately 1,680 mm, most of which falls between April and September (Duzgoren-Aydin et al. 2006b).
Samples were collected from 35 sites in the metropolitan area of Guangzhou during 21-23 January 2009 (Fig. 1). The sampling period was preceded by 16 consecutive sunny days in Guangzhou. The detailed sampling locations and average daily traffic volumes are listed in the Electronic Supplementary Material Table S1. All the samples were collected along the curb in streets with various traffic volumes using a dust collector (FC8262, Philips Inc.). The sampling width from the curb, length along the curb, and area were $20-40 \mathrm{~cm}, 2-6 \mathrm{~m}$, and $0.5-2.0 \mathrm{~m}^{2}$, respectively. A different dust bag was used at each location to avoid crosscontamination of the samples. With the exception of one location (the intersection between Erheng Road and New Street, Yuan Village), the roads are wide, with 4-12 traffic lanes. The average daily traffic at the sampling sites was estimated to range from 5,000 to 80,000 vehicles.

The collected road dust samples were dried in an oven at $60{ }^{\circ} \mathrm{C}$ for 1 day and then sieved $(<2 \mathrm{~mm})$ to remove large plant and plastic debris, gravel-sized materials, and cigarette butts. They were further sieved to isolate the $<0.075 \mathrm{~mm}$ grain-size fraction for analysis, based on the high contribution of the fine grain-size fraction to airborne particulate matter and transport of material into the water system (Owens et al. 2011). All samples were homogenized and ground with a pestle and agate mortar, and kept in a desiccator prior to chemical digestion.

\subsection{Analytical methods and quality control}

All of the heavy metal analysis was performed at the Guangzhou Institute of Geochemistry, Chinese Academy of Sciences, Guangzhou, China. A strong acid digestion
Fig. 1 Regional map of China showing the location of Guangzhou (a) and sampling sites (b)

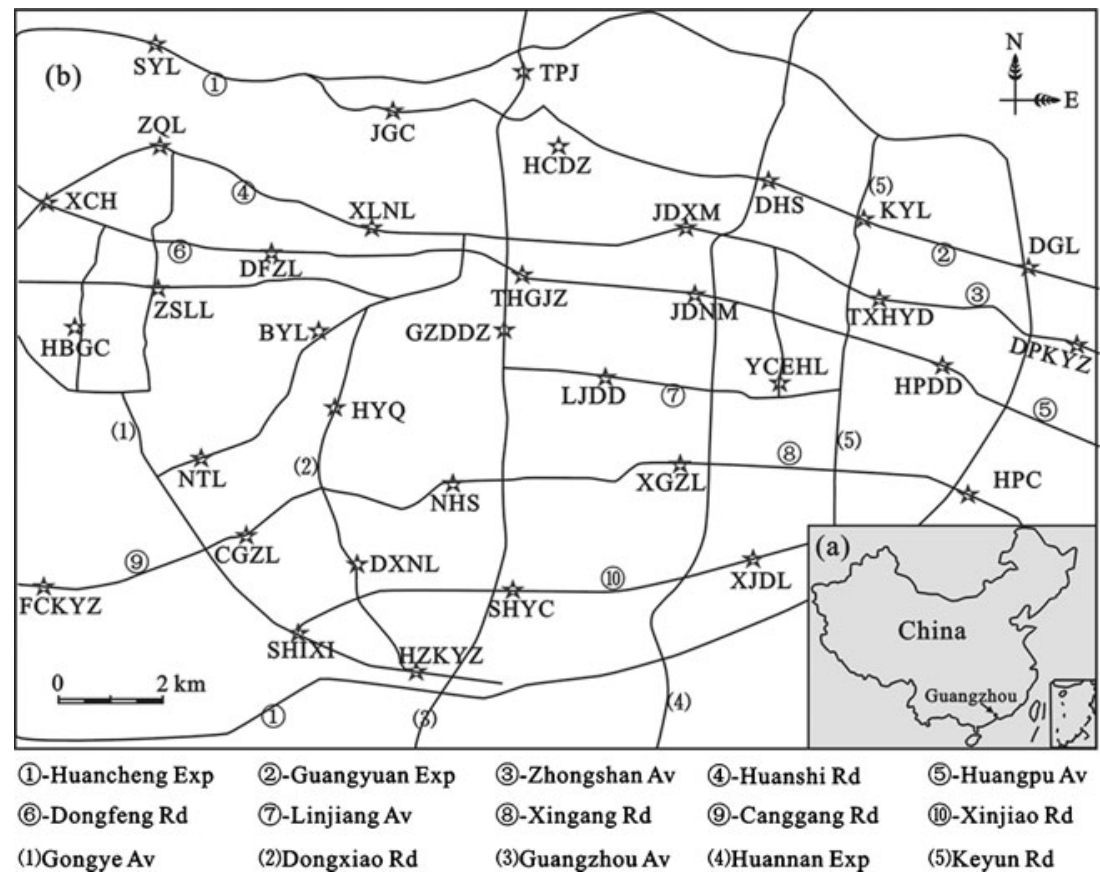


method was used to dissolve the samples. For this, about $40 \mathrm{mg}$ samples of road sediment from each site were dissolved in distilled $\mathrm{HF}+\mathrm{HNO}_{3}+\mathrm{HClO}_{4}$ in $15 \mathrm{ml} \mathrm{Savillex}{ }^{\circledR}$ Teflon screw-cap beakers and high-pressure Teflon bombs at $190{ }^{\circ} \mathrm{C}$ for 2 days. Samples were then dried and subsequently diluted to $80 \mathrm{ml}$ with $3 \% \mathrm{HNO}_{3}$ solution. Heavy metal concentrations were measured by ICP-MS with a Perkin-Elmer Elan 6000 mass spectrometer. A blank (control) solution (no road sediment) was prepared, and the total procedural blank was $<50 \mathrm{pg}$ for all heavy metal elements. Rhodium was used as an internal standard to correct for matrix effects and instrument drift. Precision for all heavy metal elements was estimated to be $5 \%(2 \sigma)$, and accuracy was better than $5 \%(2 \sigma)$ for analyses of the Chinese standard materials GSD-9, GSD-10, and GSD-12.

$\mathrm{Pt}$ and Pd concentrations were measured by isotopic dilution-inductively coupled plasma-mass spectrometry with a Perkin-Elmer Elan 6000 mass spectrometer. Rh was measured by external standard-inductively coupled plasmamass spectrometry. Pt, Pd, and $\mathrm{Rh}$ were extracted quantitatively from the samples $(1.0-2.0 \mathrm{~g})$ into aqua regia in Carius tubes, and the spike and sample were isotopically equilibrated at $230^{\circ} \mathrm{C}$ in an oven for 2 days. $\mathrm{Pt}, \mathrm{Pd}$, and $\mathrm{Rh}$ were separated from the sample matrix by cation exchange chromatography (AG50W-X8) and solvent extraction (BPHA in $\mathrm{CCl}_{4}$ ). This analytical procedure has the potential to greatly reduce the total procedural blanks (Pearson and Woodland 2000). The digested sample solutions were transferred into $22 \mathrm{ml}$ Savillex ${ }^{\circledR}$ PFA standard vials and dried before adding $2 \mathrm{ml}$ of $6 \mathrm{~mol} \mathrm{l}^{-1} \mathrm{HCl}$ acid, and kept at $100{ }^{\circ} \mathrm{C}$ for $2 \mathrm{~h}$. Samples were then re-dried, another $5 \mathrm{ml}$ of $1.0 \mathrm{~mol}^{-1} \mathrm{HCl}$ acid was added, and the samples were kept at $100{ }^{\circ} \mathrm{C}$ for a further $2 \mathrm{~h}$. Finally, $5 \mathrm{ml}$ of Milli-Q water was added, and the diluted solutions were filtrated through a $0.45-\mu \mathrm{m}$ microporous filter membrane, and passed through the cation exchange resin. Subsequently, $30 \mathrm{ml}$ of $0.5 \mathrm{~mol} \mathrm{l}^{-1} \mathrm{HCl}$ acid was used to elute Pt, Pd, and Rh from the matrix. Samples were further purified by solvent extraction with BPHA in chloroform solution (Shinotsuka and Suzuki 2007) to remove interfering $\mathrm{Mo}, \mathrm{Zr}$, and $\mathrm{Hf}$ anion complexes. All aspects of chemical treatment were performed in a superclean laboratory to ensure low blanks.

The three reference materials (GPt-2, BHVO-2, and WPR-1; see Section 2.1) were analyzed to assess the accuracy of the analytical method. The total procedural blanks of the analytical method were controlled by adding a blank to each batch of experiments. The results for the reference materials were consistent with the $\mathrm{Pt}, \mathrm{Pd}$, and $\mathrm{Rh}$ concentrations, and were in excellent agreement with certified values and previous results. The blank levels (the average concentration of five procedural reagent blanks) of Pt, Pd, and $\mathrm{Rh}$ were 2,7 , and $3 \mathrm{pg}$, respectively. The instrumental quantification limits of $\mathrm{Pt}, \mathrm{Pd}$, and $\mathrm{Rh}$ (calculated as three times the standard deviation of ion counts obtained from the $3 \% \mathrm{HNO}_{3}$ solution measured 12 times, divided by the sensitivity determined using the $10 \mathrm{ng} \mathrm{ml}^{-1}$ PGE standard solution) were 3,10 , and $4 \mathrm{pg} \mathrm{ml}^{-1}$, respectively. Detailed analytical results for the reference materials and procedural blanks are described elsewhere ( $\mathrm{Li}$ et al. 2011). The instrumental quantification limits (unit, $10^{-9}$ ) of $\mathrm{Cr}, \mathrm{Mn}, \mathrm{Ni}, \mathrm{Cu}$, $\mathrm{Zn}, \mathrm{La}, \mathrm{Ce}, \mathrm{Mo}, \mathrm{Cd}, \mathrm{Pb}, \mathrm{Ba}$, and $\mathrm{Sc}$ (calculated as three times the standard deviation of the procedural reagent blanks measured 10 times) were 99.0, 7.8, 27.6, 8.5, 52.0, $0.5,0.5,2.6,2.7,10.9,6.8$, and 25.6 , respectively. Pt and Pd concentrations were calculated from measured ${ }^{195} \mathrm{Pt} /{ }^{194} \mathrm{Pt}$ and ${ }^{106} \mathrm{Pd} /{ }^{105} \mathrm{Pd}$ values, and a $\mathrm{Pd}-\mathrm{Pt}$ standard solution was used to correct for instrumental mass fractionation. Rh concentrations were obtained using the external standard method. Isobaric interference on Pd masses was corrected by monitoring ${ }^{200} \mathrm{Hg}$ and ${ }^{111} \mathrm{Cd}$. It was also possible to identify potential polyatomic interference in $\mathrm{Pd}$ or $\mathrm{Rh}$ from $\mathrm{CuAr}$, $\mathrm{ZnAr}, \mathrm{RbO}, \mathrm{SrO}, \mathrm{YO}$, and $\mathrm{ZrO}$ molecular species by measuring ${ }^{108} \mathrm{Pd}$ and other metallic isotopes, e.g., ${ }^{63} \mathrm{Cu},{ }^{64} \mathrm{Zn}$, ${ }^{85} \mathrm{Rb},{ }^{85} \mathrm{Sr},{ }^{89} \mathrm{Y},{ }^{90} \mathrm{Zr}$, and ${ }^{95} \mathrm{Mo}$ (Simitchiev et al. 2008). ${ }^{180} \mathrm{Hf}$ was monitored to assess the potential interference of HfO species on Pt (Simitchiev et al. 2008).

\subsection{Statistical analysis}

SPSS for Windows (version 13.0, SPSS Inc., USA) was used for descriptive, correlation, principal component, and cluster analyses. Descriptive data were obtained, including the mean, median, minimum and maximum concentrations, standard deviation (SD), coefficient of variation (CV), and skewness. Coefficients of variation (being equal to $\mathrm{SD} /$ mean) were used to assess the degree of discrete distribution of the different metal element concentrations and to indicate indirectly the activity of the selected element in the environment. In addition, correlation coefficients were calculated to determine the relationships among the elements.

Principal component analysis (PCA) and cluster analysis (CA) are the most common multivariate statistical methods used in environmental studies (e.g., Liu et al. 2003; Han et al. 2006; Lu et al. 2010). PCA is often used to reduce data and to extract latent factors (i.e., principal components, PCs) to analyze relationships among the observed variables. If there are large differences in the standard deviations of variables, PCA results vary considerably depending on whether the covariance or correlation matrix is used (Farnham et al. 2003). To aid interpretation, PCA with VARIMAX normalized rotation was applied, which could maximize the variance of the factor loadings across variables for each factor. Typically, factor loadings of $>0.71$ are regarded as excellent and $<0.32$ as very poor (García et al. 2004). When PCA with VARIMAX normalized rotation is performed, each PC score contains 
information of all of the metal elements combined into a single number, while the loadings indicate the relative contribution of each element to the score. In this study, because of the large range of concentrations of the trace elements, PCA was applied to the correlation matrix, and each variable was normalized to unit variance to ensure that each variable made an equal contribution. In addition, all the principal factors extracted from the variables were retained with eigenvalues $>1.0$, as suggested by the Kaiser criterion (Kaiser 1960).

Cluster analysis was performed to further classify elements from different sources on the basis of similarities between their chemical properties. Hierarchical cluster analysis assisted in identifying relatively homogeneous groups of variables, using an algorithm that starts with each variable in a separate cluster and combines clusters until only one is left. As the variables have large differences in scaling, standardization was performed before computing proximities, which can be done automatically by the hierarchical cluster analysis procedure. A dendrogram was constructed to assess the cohesiveness of the clusters formed, in which correlations among elements are readily apparent. The CA is complementary to PCA.

\subsection{Enrichment factor}

The enrichment factor (EF) can be used to differentiate heavy metals originating from human and natural sources and, therefore, to assess the degree of anthropogenic influence on heavy metal contamination. One technique in this regard is normalization of a tested element against a reference element such as $\mathrm{Al}, \mathrm{Fe}, \mathrm{Mn}, \mathrm{Sc}, \mathrm{Ti}, \mathrm{Zr}$, etc. (Reimann and Caritat 2000; Hernandez et al. 2003; Conrad and Chisholm-Brause 2004; Han et al. 2006). Sc was chosen as the reference element in this study based on the descriptive statistical results and its geochemical properties. EFs were calculated using the modified formula suggested by Buat-Menard and Chesselet (1979):

$\mathrm{EF}(i)=\left[C(i)_{\text {sample }} / C(X)_{\text {sample }}\right] /\left[C(i)_{\text {reference }} / C(X)_{\text {reference }}\right]$

where $C(i)_{\text {sample }}$ is the concentration of the examined element in road sediment, $C(X)_{\text {sample }}$ is the concentration of the reference element in road sediment, $C(i)_{\text {reference }}$ is the background value of the examined element in soil, and $C(X)_{\text {reference }}$ is the background value of the reference element in soil.

EFs close to 1 indicate a crustal origin, while those $>10$ are considered to have a non-crustal source (Liu et al. 2003). Furthermore, EFs can be used to classify the degree of heavy metal contamination using five categories (Sutherland 2000): (1) $\mathrm{EF}<2$ (depletion to minimal enrichment); (2) $\mathrm{EF}=2-5$ (moderate enrichment); (3) $\mathrm{EF}=5-20$ (significant enrichment); (4) $E F=20-40$ (very high enrichment); and (5) $\mathrm{EF}>40$ (extremely high enrichment).

\section{Results and discussion}

\subsection{Heavy metal concentrations}

Table 1 summarizes the descriptive statistical data for platinum-group and other traffic-related heavy metal concentrations measured in road sediment $(n=35)$ from Guangzhou, as well as background (reference) values for soils in China (Chi and Yan 2007). Despite the introduction of vehicle exhaust catalysts in China some 20 years after that in other developed countries, PGE concentrations in road sediment from Guangzhou are similar to, or slightly higher than, those reported in other studies (e.g., Leopold et al. 2008; Sutherland et al. 2008; Prichard et al. 2009). However, the concentration of other traffic-related trace metals was generally higher for the Guangzhou samples than found elsewhere (e.g., Christoforidis and Stamatis 2009; Apeagyei et al. 2011; Duong and Lee 2011), particularly for $\mathrm{Cd}, \mathrm{Cu}, \mathrm{Pb}$, and $\mathrm{Zn}$.

Compared with background values in soil, mean concentrations of Pt, Pd, and Rh were much higher in road sediment from Guangzhou. For example, the mean concentration of Rh in road sediment was more than 1,400 times higher than the reference value. Ratios of mean concentrations in road sediment to corresponding reference values (in soil), in decreasing order, were $\mathrm{Rh}>\mathrm{Pd}>\mathrm{Pt}>\mathrm{Cd}>\mathrm{Zn}>\mathrm{Pb}>\mathrm{Cu}>\mathrm{Mo}>\mathrm{Cr}>\mathrm{Ni}$. In contrast, the mean concentrations of $\mathrm{Mn}, \mathrm{La}, \mathrm{Ce}$, and $\mathrm{Ba}$ were comparable to their reference values. This result indicates that $\mathrm{Mn}, \mathrm{La}, \mathrm{Ce}$, and $\mathrm{Ba}$ were derived mainly from natural sources, while the other elements were influenced by anthropogenic emissions. Skewness values also showed that only $\mathrm{Mn}, \mathrm{La}, \mathrm{Ce}$, and $\mathrm{Ba}$ approached a normal distribution, while the other metal elements were positively skewed towards lower concentrations.

\subsection{Correlation coefficient analysis}

Table 2 lists the Spearman correlation coefficients among the 14 metal elements measured in road sediment $(n=35)$ from Guangzhou. The PGEs (Pt, Pd, and Rh) show significant linear positive correlations, which could indicate a common source. Significant positive correlations are also found between $\mathrm{Mo}$ and $\mathrm{Pt}, \mathrm{Pd}, \mathrm{Rh}, \mathrm{Mn}, \mathrm{Cu}$, and $\mathrm{Pb}$. $\mathrm{La}$ and Ce show a very strong positive correlation $(r=0.982)$, which likely reflects their similar geochemical nature. However, they each show a weak correlation with $\mathrm{Pt}, \mathrm{Pd}, \mathrm{Rh}$, and $\mathrm{Mn}$. Though $\mathrm{Pb}$ and $\mathrm{Zn}$ have similar geochemical properties, they show a very weak correlation, probably reflecting the influence of traffic and industrial activities. 
Table 1 Descriptive statistics for PGEs and other heavy metal contaminants in road sediment from Guangzhou

\begin{tabular}{lcccccccc}
\hline Element $^{\mathrm{a}}$ & Minimum & Maximum & Mean & Median & SD & CV & Skewness & Background $^{\mathrm{b}}$ \\
\hline $\mathrm{Pt}$ & $12.35(18.0)$ & $152.8(249)$ & 68.24 & 62.82 & 40.53 & 0.59 & 0.42 & 0.50 \\
$\mathrm{Pd}$ & $9.69(13.2)$ & $262.8(330)$ & 93.15 & 72.34 & 70.17 & 0.75 & 0.66 & 0.65 \\
$\mathrm{Rh}$ & $4.09(184)$ & $64.35(3086)$ & 23.85 & 18.86 & 15.28 & 0.64 & 1.04 & 0.017 \\
$\mathrm{Cr}$ & $80.96(1.00)$ & $305.4(3.92)$ & 147.5 & 133.2 & 50.06 & 0.34 & 1.54 & 65 \\
$\mathrm{Mn}$ & $527.6(0.73)$ & $920.7(1.29)$ & 712.3 & 695.2 & 108.4 & 0.15 & 0.17 & 600 \\
$\mathrm{Ni}$ & $20.32(0.63)$ & $84.13(2.68)$ & 47.24 & 43.07 & 14.62 & 0.31 & 0.75 & 26 \\
$\mathrm{Cu}$ & $114.8(3.75)$ & $290.5(10.5)$ & 177.5 & 175.3 & 47.25 & 0.27 & 0.88 & 24 \\
$\mathrm{Zn}$ & $466.5(5.42)$ & $4,086(54.2)$ & 1,254 & 911.5 & 1,090 & 0.87 & 2.03 & 68 \\
$\mathrm{La}$ & $30.08(0.61)$ & $69.87(1.50)$ & 47.50 & 48.94 & 10.30 & 0.22 & 0.12 & 38 \\
$\mathrm{Ce}$ & $59.35(0.63)$ & $150.2(1.71)$ & 96.62 & 97.85 & 22.97 & 0.24 & 0.34 \\
$\mathrm{Mo}$ & $2.97(2.85)$ & $10.33(10.2)$ & 4.91 & 4.82 & 1.46 & 0.30 & 1.93 & 72 \\
$\mathrm{Cd}$ & $1.67(14.22)$ & $6.74(64.6)$ & 3.00 & 2.73 & 1.16 & 0.39 & 1.72 & 0.8 \\
$\mathrm{~Pb}$ & $71.67(2.64)$ & $501.3(19.5)$ & 198.1 & 192.1 & 79.49 & 0.40 & 2.22 \\
$\mathrm{Ba}$ & $479(0.74)$ & $792.5(1.44)$ & 619.0 & 605.0 & 89.0 & 0.14 & 0.33 \\
$\mathrm{Sc}$ & 12.2 & 15.3 & 13.5 & 13.5 & 0.8 & 0.06 & 0.26 & 23 \\
\hline
\end{tabular}

Data in parentheses are the enrichment factor $(\mathrm{EF}) ; \mathrm{EF}(i)=[C(i) / C(\mathrm{Sc})]_{\text {sample }} /[C(i) / C(\mathrm{Sc})]_{\text {reference }}$; see the text for details

${ }^{\mathrm{a}}$ The unit of measurement for Pt, $\mathrm{Pd}$, and Rh concentrations is $\mathrm{ng} \mathrm{g}^{-1}$; for all other elements, it is $\mu \mathrm{g} \mathrm{g}^{-1}$.

${ }^{\mathrm{b}}$ Chi and Yan (2007)

$\mathrm{Ba}$ and $\mathrm{Mn}$ are generally poorly correlated with the other metal elements, possibly reflecting a different source from the other metals.

\subsection{Principal component analysis}

Principal component analysis was used to assist in the identification of sources of heavy metals in road sediment by applying VARIMAX rotation with Kaiser normalization (see Section 2.4). By extracting the eigenvalues and eigenvectors from the correlation matrix, we calculated the number of significant factors and the proportion of variance explained by each factor. Table 3 shows the results of the factor loadings with a VARIMAX rotation, as well as initial eigenvalues and communalities. These data indicate that the elemental composition of road sediment is dominated by five PCs (PC1-PC5) with loadings of $27.50,19.57,13.43,9.08$, and $8.15 \%$, respectively.

Table 2 Spearman correlation matrix for platinum-group elements and other trace metal concentrations

\begin{tabular}{|c|c|c|c|c|c|c|c|c|c|c|c|c|c|c|}
\hline & $\mathrm{Pt}$ & $\mathrm{Pd}$ & $\mathrm{Rh}$ & $\mathrm{Cr}$ & $\mathrm{Mn}$ & $\mathrm{Ni}$ & $\mathrm{Cu}$ & $\mathrm{Zn}$ & $\mathrm{La}$ & $\mathrm{Ce}$ & Mo & $\mathrm{Cd}$ & $\mathrm{Pb}$ & $\mathrm{Ba}$ \\
\hline $\mathrm{Pt}$ & 1.000 & & & & & & & & & & & & & \\
\hline $\mathrm{Pd}$ & $0.839 * *$ & 1.000 & & & & & & & & & & & & \\
\hline $\mathrm{Rh}$ & $0.844 * *$ & $0.808 * *$ & 1.000 & & & & & & & & & & & \\
\hline $\mathrm{Cr}$ & 0.266 & 0.307 & 0.257 & 1.000 & & & & & & & & & & \\
\hline Mn & 0.187 & 0.224 & 0.234 & $0.397 *$ & 1.000 & & & & & & & & & \\
\hline $\mathrm{Ni}$ & -0.049 & -0.114 & 0.100 & 0.227 & -0.137 & 1.000 & & & & & & & & \\
\hline $\mathrm{Cu}$ & 0.109 & -0.045 & 0.170 & 0.330 & -0.013 & $0.515^{* *}$ & 1.000 & & & & & & & \\
\hline $\mathrm{Zn}$ & 0.117 & 0.051 & 0.322 & 0.118 & 0.154 & $0.397 *$ & 0.120 & 1.000 & & & & & & \\
\hline $\mathrm{La}$ & 0.296 & 0.260 & 0.248 & 0.144 & 0.319 & -0.147 & 0.040 & -0.136 & 1.000 & & & & & \\
\hline $\mathrm{Ce}$ & 0.359 & 0.298 & 0.317 & 0.147 & 0.352 & -0.197 & 0.047 & -0.088 & $0.982 * *$ & 1.000 & & & & \\
\hline Mo & $0.435^{*}$ & $0.399 *$ & $0.606^{* *}$ & 0.344 & $0.397 *$ & 0.101 & $0.413^{*}$ & $0.507 * *$ & 0.161 & 0.237 & 1.000 & & & \\
\hline $\mathrm{Cd}$ & 0.139 & 0.231 & 0.183 & 0.340 & 0.049 & 0.228 & 0.375 & 0.328 & -0.137 & -0.090 & 0.321 & 1.000 & & \\
\hline $\mathrm{Pb}$ & 0.184 & 0.347 & 0.273 & 0.347 & 0.234 & -0.134 & 0.067 & 0.145 & 0.366 & 0.360 & $0.460^{*}$ & $0.478 *$ & 1.000 & \\
\hline $\mathrm{Ba}$ & 0.119 & 0.181 & 0.275 & 0.227 & 0.132 & 0.251 & $0.405^{*}$ & 0.123 & -0.126 & -0.121 & 0.295 & 0.310 & 0.310 & 1.000 \\
\hline
\end{tabular}


Table 3 Rotated component matrix for road sediment data in Guangzhou (PCA loadings $>0.4$ are shown in italics)

\begin{tabular}{|c|c|c|c|c|c|c|}
\hline \multirow[t]{2}{*}{ Element } & \multicolumn{5}{|c|}{ Component } & \multirow[t]{2}{*}{ Communitie } \\
\hline & 1 & 2 & 3 & 4 & 5 & \\
\hline $\mathrm{Pt}$ & 0.94 & 0.14 & 0.07 & 0.01 & -0.04 & 0.90 \\
\hline $\mathrm{Pd}$ & 0.93 & 0.10 & -0.01 & 0.09 & 0.14 & 0.91 \\
\hline $\mathrm{Rh}$ & 0.91 & 0.01 & 0.14 & 0.20 & -0.05 & 0.89 \\
\hline $\mathrm{Cr}$ & 0.12 & 0.21 & 0.76 & 0.03 & 0.22 & 0.69 \\
\hline $\mathrm{Mn}$ & 0.08 & 0.31 & 0.11 & 0.78 & -0.13 & 0.75 \\
\hline $\mathrm{Ni}$ & -0.09 & -0.48 & 0.74 & 0.01 & -0.17 & 0.81 \\
\hline $\mathrm{Cu}$ & -0.03 & -0.03 & 0.78 & -0.02 & 0.08 & 0.61 \\
\hline $\mathrm{Zn}$ & 0.13 & -0.78 & 0.12 & 0.02 & -0.06 & 0.64 \\
\hline $\mathrm{La}$ & 0.22 & 0.87 & 0.13 & 0.10 & 0.03 & 0.84 \\
\hline $\mathrm{Ce}$ & 0.30 & 0.87 & 0.12 & 0.06 & 0.01 & 0.86 \\
\hline Mo & 0.30 & 0.10 & 0.71 & 0.26 & 0.03 & 0.67 \\
\hline $\mathrm{Cd}$ & 0.12 & -0.47 & 0.26 & 0.02 & 0.61 & 0.68 \\
\hline $\mathrm{Pb}$ & -0.04 & 0.25 & 0.04 & 0.06 & 0.89 & 0.86 \\
\hline $\mathrm{Ba}$ & 0.17 & -0.18 & 0.03 & 0.81 & 0.21 & 0.76 \\
\hline $\begin{array}{l}\text { Initial } \\
\text { Eigenvalues }\end{array}$ & 3.85 & 2.74 & 1.88 & 1.27 & 1.14 & \\
\hline $\begin{array}{c}\text { Percent of } \\
\text { variance }\end{array}$ & 27.50 & 19.57 & 13.43 & 9.08 & 8.15 & \\
\hline $\begin{array}{l}\text { Cumulative } \\
\text { percent }\end{array}$ & 27.50 & 47.07 & 60.50 & 69.58 & 77.73 & \\
\hline
\end{tabular}

Collectively, these PCs account for $77.73 \%$ of the total variance. Based on the loading distributions, $\mathrm{Pt}, \mathrm{Pd}$, and $\mathrm{Rh}$ are strongly associated with $\mathrm{PC} 1$, but very small loadings are found for the other PCs. This suggests that the distributions of $\mathrm{Pt}, \mathrm{Pd}$, and $\mathrm{Rh}$ are controlled by one major factor (i.e., one source). PC2 is dominated by La, $\mathrm{Ce}, \mathrm{Zn}, \mathrm{Cd}$, and $\mathrm{Ni}$, which account for $19.57 \%$ of the total variance. With respect to $\mathrm{PC}$, the $\mathrm{Cd}, \mathrm{Ni}$, and $\mathrm{Zn}$ loadings are negative $(-0.47,-0.48$, and -0.78 , respectively) and not as high as the loadings of the other elements of this group. This finding suggests a quasi-independent behavior within the group, and a different source. $\mathrm{Cr}, \mathrm{Ni}, \mathrm{Cu}$, and $\mathrm{Mo}$ are closely associated with $\mathrm{PC} 3 ; \mathrm{Ba}$ and $\mathrm{Mn}$ with $\mathrm{PC} 4$; and $\mathrm{Pb}$ and $\mathrm{Cd}$ with PC5.

\subsection{Cluster analysis}

Cluster analysis was applied to standardized bulk concentration data using Ward's method (Han et al. 2006) with Euclidian distances as the criterion for forming clusters. The CA results for the heavy metals are shown in Fig. 2 as a dendrogram. Three clusters were identified: (1) Mo-Cd-Rh-Ni-La$\mathrm{Pt}-\mathrm{Pd}-\mathrm{Ce}-\mathrm{Cr}-\mathrm{Cu}-\mathrm{Pb}$; (2) $\mathrm{Mn}-\mathrm{Ba}$; and (3) $\mathrm{Zn}$. This finding is in agreement with the PCA results as a whole (Section 3.3). Clusters 1 and 2 join together at a relatively high level, possibly implying a common source.

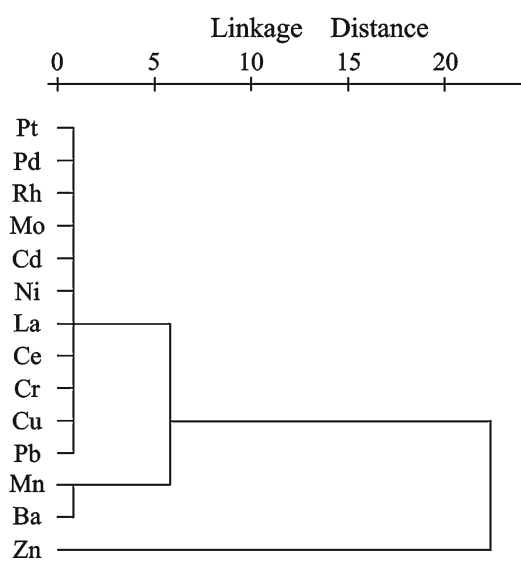

Fig. 2 Dendrogram derived using Ward's method of hierarchical cluster analysis for 14 different elements

\subsection{Source identification}

It has been well documented that the elemental composition of road sediment can reflect mixed origins, including geogenic and a wide range of anthropogenic sources (e.g., de Miguel et al. 1997; Duzgoren-Aydin et al. 2006b). Therefore, it is difficult to ascribe a specific source to heavy metals in urban environments. In this study, multivariate statistical analysis was used to identify the sources of platinum-group and other traffic-related heavy metals in road sediment from Guangzhou.

Compared with background values measured in soil, the extremely elevated concentrations of $\mathrm{Pt}, \mathrm{Pd}, \mathrm{Rh}, \mathrm{Zn}, \mathrm{Cd}, \mathrm{Pb}$, $\mathrm{Cu}, \mathrm{Cr}, \mathrm{Mo}$, and $\mathrm{Ni}$ in Guangzhou road sediment suggest anthropogenic sources. Other elemental concentrations (La, $\mathrm{Ce}, \mathrm{Mn}$, and $\mathrm{Ba}$ ) were slightly higher than, or approximately equal to, their corresponding background values in most of the samples, likely indicating a geogenic origin. Values of skewness and coefficients of variation (CV) further suggested these origins. The correlation coefficient analysis suggested that $\mathrm{Pt}, \mathrm{Pd}$, and $\mathrm{Rh}$ have a common source, while $\mathrm{La}$ and $\mathrm{Ce}$ have a different common source. PCA and CA results were consistent with these interpretations. Based on all of the analyses carried out, four main sources (with corresponding cluster elements) could be identified: (1) Pt, $\mathrm{Pd}$, and Rh represented traffic sources; (2) La, Ce, Mn, and $\mathrm{Ba}$ were derived mainly from natural sources, although $\mathrm{La}$ and $\mathrm{Ce}$ also had traffic sources, and $\mathrm{Mn}$ and $\mathrm{Ba}$ also had minor industrial sources; (3) $\mathrm{Cr}, \mathrm{Ni}, \mathrm{Cu}, \mathrm{Mo}, \mathrm{Cd}$, and $\mathrm{Pb}$ had mixed sources of traffic and industry; and (4) $\mathrm{Zn}$ originated mainly from industrial sources.

The first group of elements ( $\mathrm{Pt}, \mathrm{Pd}$, and $\mathrm{Rh}$ ), which have the highest enrichment factors among the examined elements in comparison with reference values, show strong positive correlations in the PCA and correlation coefficient analysis and are classified together in the CA. These three metals are the active catalytic materials in vehicle exhaust 
converters and have consequently become concentrated in urban road sediment since their introduction (Gómez et al. 2001; Leopold et al. 2008; Prichard et al. 2009). In Guangzhou, higher concentrations of these elements were found in samples collected from high-traffic sites, indicating the elements originated from traffic sources (i.e., from vehicle exhaust catalysts).

Descriptive statistical data indicate that the second group of elements identified in the analyses ( $\mathrm{La}, \mathrm{Ce}, \mathrm{Mn}$, and $\mathrm{Ba}$ ) was derived mainly from natural sources. Based on the correlation analysis, PCA and CA, this group can be further subdivided into two sub-clusters: (1) La and Ce are significantly correlated, and (2) Mn and Ba are well correlated, although they show a weaker correlated in the correlation coefficient analysis. The maximum concentrations of $\mathrm{La}$, $\mathrm{Ce}, \mathrm{Mn}$, and $\mathrm{Ba}$ are 1.5-2 times greater than the corresponding background values of soil, indicating some anthropogenic influence. La and Ce are moderately correlated with $\mathrm{Pt}, \mathrm{Pd}$, and $\mathrm{Rh}$ in the correlation coefficient analysis and PCA, and are classified together with PGEs in the $\mathrm{CA}$, suggesting a traffic source. $\mathrm{Mn}$ and $\mathrm{Ba}$ are strongly correlated in the PCA and are clearly separated from the other metals in $\mathrm{CA}$, suggesting an anthropogenic source other than traffic (e.g., rubber production, lubricating oil additives, fuel synthesis, fuel combustion, phosphate fertilisers, and sewage sludge; Sutherland 2000).

The third group of elements $(\mathrm{Cr}, \mathrm{Ni}, \mathrm{Cu}, \mathrm{Mo}, \mathrm{Cd}$, and $\mathrm{Pb})$ is significantly correlated in the correlation coefficient analysis and is classified together with PGEs in the CA, indicating a traffic source. However, this group is associated with two principal components ( $\mathrm{PC} 3$ for $\mathrm{Cr}, \mathrm{Ni}, \mathrm{Cu}$, and $\mathrm{Mo}$; $\mathrm{PC} 5$ for $\mathrm{Cd}$ and $\mathrm{Pb}$ ) and is separate from PGEs in the PCA. This result suggests that the third group of elements was not derived from traffic sources alone. In fact, $\mathrm{Cr}, \mathrm{Ni}, \mathrm{Cu}, \mathrm{Cd}$, and $\mathrm{Pb}$ may originate from various industries besides traffic. For example, other potential sources of $\mathrm{Cd}$ include lubricating oil, diesel oil, tyres, phosphate fertilisers, insecticides, electroplating, pigments, batteries, coal and oil combustion, nonferrous metal production, refuse incineration, and iron and steel manufacturing. In addition to diesel fuel and vehicle exhaust, Ni can originate from lubricating oil, metal plating, brushing wear, brake lining wear, phosphate fertilisers, and storage batteries (Sutherland 2000). Thus, the third group of elements identified in the analyses is suggested to have originated from combined industrial and traffic sources.

The fourth group ( $\mathrm{Zn})$ is separate from the other elements in the CA, suggesting a distinct source. The $\mathrm{Zn}$ in Guangzhou road sediment shows the highest mean concentration, and largest $\mathrm{CV}$ and skewness. In addition, $\mathrm{Zn}$ is negatively correlated with $\mathrm{La}$ and $\mathrm{Ce}$ in the correlation coefficient analysis and the PCA. This finding suggests anthropogenic sources. $\mathrm{Zn}$ is typically a traffic-related element that may originate from fossil fuels, combustion exhaust, brake lining, and rubber tyres (Councell et al. 2004). However, traffic does not appear to be the main source of $\mathrm{Zn}$ in this study, and may have originated from other sources such as grease, batteries, galvanising, plating, air-conditioning ducts, pesticides, phosphate fertilisers, transmission fluid, asphalt paving, concrete, smelting operations, incineration, and wood combustion (Sutherland 2000). For example, a significant amount of asphalt was used as paving for the 2010 Guangzhou Asian games, which could have contributed to the significantly elevated levels of $\mathrm{Zn}$ measured in road sediment in the present study.

\subsection{Enrichment factor analysis}

EFs of the different elements (normalized against Sc) are shown in Fig. 3. The three PGEs, especially Rh, have unusually high EFs, suggesting anthropogenic sources. In contrast, $\mathrm{La}, \mathrm{Ce}, \mathrm{Mn}$, and $\mathrm{Ba}$ have EFs of $<2$ in all road sediment samples, confirming that their origin was mainly from natural sources. Other elements $(\mathrm{Cr}, \mathrm{Ni}, \mathrm{Cu}, \mathrm{Zn}, \mathrm{Mo}$, $\mathrm{Cd}$, and $\mathrm{Pb}$ ) have EFs indicating low deficiency to extremely high enrichment, but maximum EFs $>3$ suggest some anthropogenic influence (Han et al. 2006).

The mean EFs ranked in decreasing order are as follows: $\mathrm{Rh}>\mathrm{Pd}>\mathrm{Pt}>\mathrm{Cd}>\mathrm{Zn}>\mathrm{Pb}>\mathrm{Cu}>\mathrm{Mo}>\mathrm{Cr}>\mathrm{Ni}>\mathrm{Ce}>\mathrm{La}>\mathrm{Ba}>$ $\mathrm{Mn}$. This order can be interpreted to indicate the relative levels of contamination of each element in road sediment from Guangzhou. Pt, Pd, and Rh have mean EFs above 40, suggesting extremely high levels of contamination; $\mathrm{Cr}, \mathrm{Mn}$, $\mathrm{Ni}, \mathrm{La}, \mathrm{Ce}$, and $\mathrm{Ba}$ have mean $\mathrm{EFs}$ of $<2$, representing depletion to minimal levels of contamination; and $\mathrm{Cd}, \mathrm{Zn}$, $\mathrm{Pb}, \mathrm{Cu}$, and Mo have mean EFs between 5 and 40, indicating significant to very high contamination. Maximum EFs may also reflect the degree to which each metal is affected by local

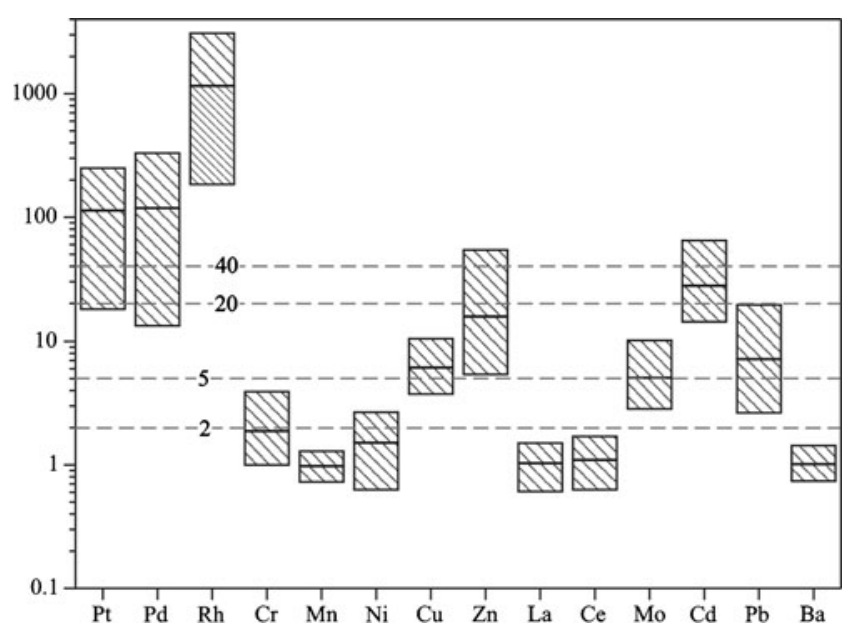

Fig. 3 Boxplot of enrichment factors for traffic-related heavy metals in road sediment from Guangzhou (all EFs are log normalized; the height of each box represents the range; the thick line inside each box represents the mean) 
pollution. The maximum EFs of $\mathrm{Pt}, \mathrm{Pd}, \mathrm{Rh}, \mathrm{Cd}$, and $\mathrm{Zn}$ are above 50, suggesting extremely high contamination of local road sediment; the maximum $\mathrm{EF}$ of $\mathrm{Pb}$ is 19.5 , equating to very high contamination; $\mathrm{Cu}$ and Mo have maximum EFs of 10.5 and 10.2, respectively, indicating significant contamination. The EFs of $\mathrm{La}, \mathrm{Ce}, \mathrm{Mn}$, and $\mathrm{Ba}$ are very low $(0.61-1.50,0.63-1.71,0.73-1.29$, and $0.73-1.77$, respectively), reflecting minimal levels of contamination. These observations show that EFs can be an effective tool for evaluating the contribution of anthropogenic and natural sources to heavy metal contamination of road sediment.

\section{Conclusions}

This study analyzed the concentrations and sources of the platinum-group and other traffic-related heavy metals, including Pt, Pd, Rh, Cr, Mn, Ni, Cu, Zn, La, Ce, Mo, Cd, Pb, and $\mathrm{Ba}$, in road sediment samples collected from Guangzhou. The mean concentrations of these heavy metals are higher than corresponding background values measured in soils in China. This was particularly true for $\mathrm{Pt}, \mathrm{Pd}, \mathrm{Rh}, \mathrm{Cd}$, and $\mathrm{Zn}$, for which we obtained significantly higher concentrations than background values.

Based on coefficients of variation and skewness values, and a comparison between concentrations measured in road sediment and soil, the heavy metals were classified into two main groups according to their sources: geogenic and anthropogenic. PCA, CA, and correlation coefficient analysis enabled four further groups to be identified. First, Pt, Pd, and $\mathrm{Rh}$ were derived from traffic sources. Second, $\mathrm{La}, \mathrm{Ce}$, $\mathrm{Mn}$, and $\mathrm{Ba}$ were derived mainly from natural sources, although $\mathrm{La}$ and $\mathrm{Ce}$ were also influenced by other traffic sources, and $\mathrm{Mn}$ and $\mathrm{Ba}$ were influenced by minor industrial sources. Third, $\mathrm{Cr}, \mathrm{Ni}, \mathrm{Cu}, \mathrm{Mo}, \mathrm{Cd}$, and $\mathrm{Pb}$ showed mixed traffic and industry sources. Fourth, Zn originated mainly from industrial sources. EF analysis supported this source identification and further indicated that contamination of road sediment in Guangzhou is extremely high for Pt, Pd, and $\mathrm{Rh}$; moderate to very high for $\mathrm{Cd}, \mathrm{Zn}, \mathrm{Pb}, \mathrm{Cu}$, and $\mathrm{Mo}$; and minimal for $\mathrm{Cr}, \mathrm{Ni}, \mathrm{La}, \mathrm{Ce}, \mathrm{Mn}$, and $\mathrm{Ba}$.

Acknowledgments This study was supported by the Natural Science Foundation of China (NSFC) through grant nos. 40806049 and 40903007. We would also like to acknowledge Dr. Zhong Chen, Weihai Xu, Dr. Li Miao, and Dr. Aaron Stallard for commenting on an early version of this manuscript.

Open Access This article is distributed under the terms of the Creative Commons Attribution License which permits any use, distribution, and reproduction in any medium, provided the original author(s) and the source are credited.

\section{References}

Apeagyei E, Bank MS, Spengler JD (2011) Distribution of heavy metals in road dust along an urban-rural gradient in Massachusetts. Atmos Environ 45:2310-2323

Artelt S, Kock H, König HP, Levsen K, Rosner G (1999) Engine dynamometer experiments: platinum emissions from differently aged three-way catalytic converters. Atmos Environ 33:3559-3567

Baldanza MAS, Mello LF, Vannice A, Noronha FB, Schmal M (2000) Adsorptive and calalytic properties of alumina-supported Pd-Mo catalysts. J Catal 192:64-76

Birmili W, Allen AG, Bary F, Harrison RM (2006) Trace metal concentrations and water solubility in size-fractionated atmospheric particles and influence of road traffic. Environ Sci Technol 40:1144-1153

Buat-Menard P, Chesselet R (1979) Variable influence of the atmospheric flux on the trace metal chemistry of oceanic suspended matter. Earth Planet Sci Lett 42:399-411

Chi QH, Yan MC (2007) Applied geochemistry — handbook of elemental abundance data. China Geological Press, Beijing (in Chinese)

Christoforidis A, Stamatis N (2009) Heavy metal contamination in street dust and roadside soil along the major national road in Kavala's region, Greece. Geoderma 151:257-263

Conrad CF, Chisholm-Brause CJ (2004) Spatial survey of trace metal contaminants in the sediments of the Elizabeth River, Virginia. Mar Pollut Bull 49:319-324

Councell TB, Duckenfield KU, Landa ER, Callender E (2004) Tirewear particles as a source of zinc to the environment. Environ Sci Technol 38:4206-4214

da Silva LID, de Souza Sarkis JE, Zotin FMZ, Carneiro MC, Neto AA, da Silva ASAG, Cardoso MJB, Monteiro MIC (2008) Traffic and catalytic converter - related atmospheric contamination in the metropolitan region of the city of Rio de Janeiro, Brazil. Chemosphere 71:677-684

de Miguel E, Llamas JF, Chacón E, Berg T, Larssen S, Røyset O, Vadset M (1997) Origin and patterns of distribution of trace elements in street dust: Unleaded petrol and urban lead. Atmos Environ 31:2733-2740

Duong TTT, Lee BK (2011) Determining contamination level of heavy metals in road dust from busy traffic areas with different characteristics. J Environ Manage 92:554-562

Duzgoren-Aydin NS (2007) Sources and characteristics of lead pollution in the urban environment of Guangzhou. Sci Total Environ 385:182-195

Duzgoren-Aydin NS, Wong CSC, Song Z, Aydin A, Li XD, You M (2006a) Fate of heavy metal contaminants in road dusts and gully sediments of Guangzhou, SE China: a chemical and mineralogical assessment. Hum Ecol Risk Assess 12:374-389

Duzgoren-Aydin NS, Wong CSC, Aydin A, Song Z, You M (2006b) Heavy metal contamination and distribution of Guangzhou, SE China. Environ Geochem Health 28:375-391

Farnham IM, Johannesson KH, Singh AK, Hodge VF, Stetzenbach KJ (2003) Factor analytical approaches for evaluating groundwater trace element chemistry data. Anal Chim Acta 490:123-138

Gagnon ZE, Newkirk C, Hicks S (2006) Impact of platinum group metals on the environment: a toxicological, genotoxic and analytical chemistry study. J Environ Sci Health A 41:397-414

Gandhi HS, Graham GW, McCabe RW (2003) Automotive exhaust catalysis. J Catal 216:433-442

García JH, Li WW, Arimoto R, Okrasinski R, Greenlee J, Walton J, Schloesslin C, Sage S (2004) Characterization and implication of potential fugitive dust sources in the Paso del Norte region. Sci Total Environ 325:95-112

Gieré R, Blackford M, Smith K (2006) TEM Study of PM2.5 emitted from coal and tire combustion in a thermal power station. Environ Sci Technol 40:6235-6240

Gómez B, Gómez M, Sanchez JL, Fernandez R, Palacios MA (2001) Platinum and rhodium distribution in airborne particulate matter and road dust. Sci Total Environ 269:131-144 
Hafeman D, Factor-Litvak P, Zhongqi C, van Geen A, Ahsan H (2007) Association between manganese exposure through drinking water and infant mortality in Bangladesh. Environ Health Perspect 115:1107-1112

Han YM, Du PX, Cao JJ, Posmentier ES (2006) Multivariate analysis of heavy metal contamination in urban dusts of Xi'an, Central China. Sci Total Environ 355:176-186

Hares RJ, Ward NI (1999) Comparison of the heavy metal content of motorway stormwater following discharge into wet biofiltration and dry detention ponds along the London Orbital (M25) motorway. Sci Total Environ 235:169-178

Hernandez L, Probst A, Probst JL, Ulrich E (2003) Heavy metal distribution in some French forest soils: evidence for atmospheric contamination. Sci Total Environ 312:195-219

Jollie D (2010) Platinum 2010. Pub Johnson Matthey 2010. pp. 54-58

Joshi UM, Vijayaraghavan K, Balasubramanian R (2009) Elemental composition of urban street dusts and their dissolution characteristics in various aqueous media. Chemosphere 77:526-533

Kaiser HF (1960) The application of electronic computers to factor analysis. Educ Psychol Meas 20:141-151

Lee CSL, Li XD, Zhang G, Li J, Ding AJ, Wang T (2007) Heavy metals and $\mathrm{Pb}$ isotopic composition of aerosols in urban and suburban areas of Hong Kong and Guangzhou, South Chinaevidence of the long-range transport of air contaminants. Atmos Environ 41:432-447

Leopold K, Maier M, Weber S, Schuster M (2008) Long-term study of palladium in road tunnel dust and sewage sludge ash. Environ Pollut 156:341-347

Li JH, Lu Y, Yin W, Gan HH, Zhang C, Deng XL, Lian J (2009) Distribution of heavy metals in agricultural soils near a petrochemical complex in Guangzhou, China. Environ Monit Assess 153:365-375

Li J, Zhong LF, Tu XL, Hu GQ, Sun YM, Liang XR, Xu JF (2011) Platinum group elements and Re-Os isotope analyses for geological samples using a single digestion procedure. Geochimica 40:1-9 (In Chinese)

Liu QT, Diamond ML, Gingrich SE, Ondov JM, Maciejczyk P, Stern GA (2003) Accumulation of metals, trace elements and semivolatile organic compounds on exterior window surfaces in Baltimore. Environ Pollut 122:51-61

Lu XW, Wang LJ, Li LY, Lei K, Huang L, Kang D (2010) Multivariate statistical analysis of heavy metals in street dust of Baoji, NW China. J Hazard Mater 173:744-749

Morcelli CPR, Figueiredo AMG, Sarkis JES, Enzweiler J, Kakazu M, Sigolo JB (2005) PGEs and other traffic-related elements in roadside soils from Sâo Paulo, Brazil. Sci Total Environ 345:81-91

Owens PN, Caley KA, Campbell S, Koiter AJ, Droppo IG, Taylor KG (2011) Total and size-fractionated mass of road-deposited sediment in the city of Prince George, British Columbia, Canada: implications for air and water quality in an urban environment. $\mathrm{J}$ Soils Sediments 11:1040-1051

Palacios MA, Gómez MM, Moldovan M, Morrison G, Rauch S, McLeod C, Ma R, Laserna J, Lucena P, Caroli S, Alimonti A, Petrucci F, Bocca B, Schramel P, Lustig S, Zischka M, Wass U, Stenbom B, Luna M, Saenz JC, Santamaria J, Torrens JM (2000) Platinum-group elements: quantification in collected exhaust fumes and studies of catalyst surfaces. Sci Total Environ 257:1-15

Park SS, Kim YJ (2005) Source contributions to fine particulate matter in an urban atmosphere. Chemosphere 59:217-226

Pearson DG, Woodland SJ (2000) Solvent extraction/anion exchange separation and determination of PGEs (Os, Ir, Pt, Pd, Ru) and Re-
Os isotopes in geological samples by isotope dilution ICP-MS. Chem Geol 165:87-107

Pratt C, Lottermoser B (2007) Mobilisation of traffic-derived trace metals from road corridors into coastal stream and estuarine sediments, Cairns, northern Australia. Environ Geol 52:437-448

Prichard HM, Sampson J, Jackson M (2009) A further discussion of the factors controlling the distribution of $\mathrm{Pt}, \mathrm{Pd}, \mathrm{Rh}$ and $\mathrm{Au}$ in road dust, gullies, road sweeper and gully flusher sediment in the city of Sheffield, UK. Sci Total Environ 407:1715-1725

Qiu Y, Guan D, Song W, Huang K (2009) Capture of heavy metals and sulfur by foliar dust in urban Huizhou, Guangdong Province, China. Chemosphere 75:447-452

Reimann C, Caritat Pd (2000) Intrinsic flaws of element enrichment factors (EFs) in environmental geochemistry. Environ Sci Technol 34:5084-5091

Salma I, Maenhaut W (2006) Changes in elemental composition and mass of atmospheric aerosol pollution between 1996 and 2002 in a Central European city. Environ Pollut 143:479-488

Shinotsuka K, Suzuki K (2007) Simultaneous determination of platinum group elements and rhenium in rock samples using isotope dilution inductively coupled plasma mass spectrometry after cation exchange separation followed by solvent extraction. Anal Chim Acta 603:129-139

Simitchiev K, Stefanova V, Kmetov V, Andreev G, Sanchez A, Canals A (2008) Investigation of ICP-MS spectral interferences in the determination of $\mathrm{Rh}, \mathrm{Pd}$ and $\mathrm{Pt}$ in road dust: assessment of correction algorithms via uncertainty budget analysis and interference alleviation by preliminary acid leaching. Talanta 77:889896

Sutherland RA (2000) Bed sediment-associated trace metals in an urban stream, Oahu, Hawaii. Environ Geol 39:611-627

Sutherland RA (2003) Lead in grain size fractions of road-deposited sediment. Environ Pollut 121:229-237

Sutherland RA, Graham Pearson D, Ottley CJ (2008) Grain size partitioning of platinum-group elements in road-deposited sediments: Implications for anthropogenic flux estimates from autocatalysts. Environ Pollut 151:503-515

Taylor KG, Owens PN (2009) Sediments in urban river basins: a review of sediment-contaminant dynamics in an environmental system conditioned by human activities. J Soils Sediments 9:281303

Wasserman GA, Liu X, Parvex F, Ahsan H, Levy D, Factor-litvak P, Kline J, van Geen A, Slavkovich V, Lolacono NJ, Cheng Z, Zheng Y, Graziano JH (2006) Water manganese exposure and children's intellectual function in Araihazar, Bangladesh. Environ Health Perspect 114:124-129

Weiss B (2006) Economic implications of manganese neurotoxicity. Neuro Toxicol 27:362-368

Wong CSC, Li XD, Zhang G, Qi SH, Peng XZ (2003) Atmospheric deposition of heavy metals in the Pearl River Delta, China. Atmos Environ 37:767-776

Zereini F, Wiseman C, Magnus Beyer J, Artelt S, Urban H (2001) Platinum, lead and cerium concentrations of street particulate matter (Frankfurt am Main, Germany). J Soils Sediments 1:188195

Zheng J, Tan M, Shibata Y, Tanaka A, Li Y, Zhang G, Zhang Y, Shan Z (2004) Characteristics of lead isotope ratios and elemental concentrations in PM10 fraction of airborne particulate matter in Shanghai after the phase-out of leaded gasoline. Atmos Environ 38:1191-1200

Zotin FMZ, Gómez OFM, Oliveira CH, Alcover NA, Cardoso MJB (2005) Automotive catalyst deactivation: case studies. Catal Today 107(108):157-167 